\title{
Pengaruh Keturunan, Obesitas dan Gaya Hidup yang Mempengaruhi Risiko Hipertensi pada Lansia di Wilayah Kerja Puskesmas Pandak II Bantul DIY Tahun 2019
}

\author{
Anis Khotimah', Parmadi Sigit Purnomo', Riza Yulina Amry ${ }^{2}$ \\ ${ }^{1}$ Program Studi Kesehatan Masyarakat, Stikes Surya Global Yogyakarta, \\ ${ }^{2}$ Program Studi Keperawatan, Stikes Surya Global Yogyakarta
}

\begin{abstract}
Abstrak
Latar belakang: Hipertensi adalah keadaan di mana tekanan darah sistolik $\geq 120 \mathrm{mmHg}$ atau Diastolik $\geq 90$ mmHg. Beberapa penyebabnya adalah keturunan, obesitas dan gaya hidup. Tujuan dari penelitian ini adalah untuk mengetahui pengaruh antara keturunan, obesitas dan gaya hidup terhadap risiko hipertensi pada lansia di wilayah kerja Puskesmas Pandak II Bantul DIY.

Metode: Penelitian ini bersifat deskriptif kuantitatif dengan pendekatan case control. Sampel diambil dengan teknik purposive sampling menggunakan perbandingan 1:1. Pengambilan sampel dengan kriteria inklusi dan eksklusi yaitu sebanyak 62 responden. Pengujian data menggunakan uji univariat dan bivariat. Instrumen penelitian yang digunakan dalam penelitian ini adalah kuesioner pengetahuan dan pengukuran pada obesitas menggunakan timbangan serta meteran dan pengukuran hipertensi menggunakan spinomamometer dan stetoskop. Hasil: Hasil dari analisis bivariat didapatkan nilai asymp sig $(0,002)<\alpha(0,05)$ yang berarti terdapat pengaruh yang sigifikan antara keturunan terhadap risiko hipertensi di wilayah kerja Puskesmas Pandak II Bantul DIY. Hasil asymp sig dari obesitas adalah $(0,575)>\alpha(0,05)$ maka Ho diterima, artinya tidak ada pengaruh yang siginifikan antara variabel obesitas terhadap risiko hipertensi di wilayah kerja Puskesmas Pandak II Bantul DIY. Dan hasil gaya hidup adalah asymp sig $(0,015)<\alpha(0,05)$ yang berarti terdapat pengaruh yang sigifikan antara gaya hidup terhadap risiko hipertensi di wilayah kerja Puskesmas Pandak II Bantul DIY.

Kesimpulan: Terdapat pengaruh yang signifikan antara keturunan terhadap risiko hipertensi, tidak terdapat pengaruh yang signifikan antara obesitas terhadap risiko hipertensi dan terdapat pengaruh yang signifikan antara gaya hidup terhadap risiko hipertensi di wilayah kerja Puskesmas Pandak II Bantul DIY.
\end{abstract}

Kata Kunci: Keturunan, Obesitas, Gaya Hidup, Hipertensi, Lansia

\section{The influence of Heredity, Obesity and lifestyle which Affect the Risk of Hypertension in the Elderly in the Working Area of Puskesmas Pandak II Bantul DIY 2019}

\begin{abstract}
Background: Hypertension is a condition where the systolic blood pressure $\geq 120 \mathrm{mmHg}$ or Diastolic $\geq 90 \mathrm{mmHg}$. Some of the causes are heredity, obesity and a sedentary lifestyle. The purpose of this study is to identify the influence of heredity, obesity and lifestyle on the risk of hypertension in the elderly in the working area of Puskesmas Pandak II Bantul DIY.

Method: This research is a descriptive quantitative case-control approach. Samples were taken with purposive sampling technique using a 1:1 comparison. Sampling with inclusion and exclusion criteria as many as 62 respondents. Testing test data using univariate and bivariate. The research instrument used in this study is a questionnaire of knowledge and measurement in obesity using the scales as well as the meter and the measurement of hypertension using the spinomamometer and stethoscope.

Results: The results of the bivariate analysis the obtained value of asymp sig $(0,002)<\alpha(0.05)$ which means there is influence significantly between offspring against the risk of hypertension in Puskesmas Pandak II Bantul DIY. The results of the asymp sig of obesity is $(0,575)>\alpha(0.05)$, then Ho is accepted, meaning that there is no influence that is significant between the variables of obesity on the risk of hypertension in Puskesmas Pandak II Bantul DIY. And life style results is asymp sig $(0,015)<\alpha(0.05)$ which means there is influence significantly between the lifestyle against the risk of hypertension in Puskesmas Pandak II Bantul DIY.

Conclusion: The conclusion from this research is there are influence which significant between breeds to the risk of hypertension, there is no significant influence of obesity on the risk of hypertension and there is significant influence between the life style on the risk of hypertension in Puskesmas Pandak II Bantul DIY.
\end{abstract}

Keywords: Heredity, Obesity, Lifestyle, Hypertension, Elderly

Korespondensi: Anis Khotimah

Email: anisintuisi2@gmail.com

Jurnal Ilmiah Kesehatan Masyarakat Volume 13 Edisi 1, 2021 


\section{PENDAHULUAN}

Hipertensi adalah suatu keadaan ketika tekanan darah di pembuluh darah meningkat secara kronis. Hal tersebut dapat terjadi karena jantung bekerja lebih keras memompa darah untuk memenuhi kebutuhan oksigen dan nutrisi tubuh. Jika dibiarkan, penyakit ini dapat mengganggu fungsi organ-organ lain, terutama organ-organ vital seperti jantung dan ginjal. Kriteria hipertensi yang digunakan pada penetapan kasus merujuk pada kriteria diagnosis JNC VII 2003, yaitu hasil pengukuran tekanan darah sistolik $\geq 140 \mathrm{mmHg}$ atau tekanan diastolik $\geq 90 \mathrm{mmHg}$. Kriteria JNC VII 2003 hanya berlaku untuk umur $\geq 18$ tahun, maka prevalensi hipertensi berdasarkan pengukuran tekanan darah dihitung hanya pada penduduk $\geq 18$ tahun. Mengingat pengukuran tekanan darah dilakukan pada penduduk umur $\geq 15$ tahun maka temuan kasus hipertensi pada umur 15-17 tahun sesuai dengan kriteria JNC VII 2003 akan dilaporkan secara garis besar sebagai tambahan informasi. ${ }^{1}$

Laporan Sistem Informasi Rumah Sakit (SIRS) Tahun 2018 menjelaskan bahwa kunjungan rawat jalan di rumah sakit, khususnya Rumah Sakit Panembahan Senopati sudah didominasi oleh penyakit tidak menular. Hal ini mempertegas bahwa Kabupaten Bantul telah terjadi transisi epidemiologi dengan semakin menonjolnya penyakit-penyakit tidak menular, khususnya hipertensi. Data hipertensi dari seluruh Puskesmas di Kabupaten Bantul tahun 2018 menjelaskan bahwa Puskesmas Pandak II menempati urutan tertinggi kejadian hipertensi dengan dengan persentase $6,48 \%$ dengan kasus sebanyak 1.254.

Dari hasil wawancara kepada salah satu petugas Puskesmas Pandak II terkait faktorfaktor pemicu hipertensi yang terjadi, diperoleh hasil faktor yang paling mempengaruhi seperti faktor keturunan, stres, kegemukan, kurang olahraga dan konsumsi lemak dan garam tinggi. Faktor keturunan bisa terjadi bila salah satu keluarga menderita hipertensi maka anak bisa terkena hipertensi, yang terjadi di wilayah kerja Puskesmas Pandak II Bantul hampir seluruhnya disebabkan oleh faktor keturunan. Selain itu juga masyarakat yang banyak mengonsumsi makanan yang tinggi garam dan banyak yang berlemak. Faktor kegemukan pada penderita hipertensi di wilayah kerja Puskesmas Pandak II ini masih banyak makan yang tidak sesuai dengan porsinya dan juga makan sehari bisa lebih dari tiga kali. Selain itu kurang nya aktivitas fisik atau olahraga juga mempengaruhi terjadi nya penyakit hipertensi pada lansia di wilayah kerja Puskesmas pandak II. Penelitian ini bertujuan untuk mengetahui pengaruh antara keturunan, obesitas dan gaya hidup terhadap risiko hipertensi pada lansia di wilayah kerja Puskesmas Pandak II Bantul DIY

\section{METODE}

Jenis penelitian ini adalah penelitian kuantitatif dengan rancangan case control. Penelitian dilakukan di Dusun Nglarang Desa Triharjo Kecamatan Pandak Kabupaten Bantul pada bulan Januari - Maret 2020. Adapun populasi dalam penelitian ini adalah semua masyarakat di Dusun Nglarang Desa Triharjo yang terdiagnosis menderita hipertensi di Puskesmas Pandak II pada Bulan Januari sampai dengan Bulan Juni 2019 dan berusia 4559 tahun yaitu sebanyak 31 orang. Sampel kasus di sini sebanyak 31 orang dengan kriteria positif penyakit hipertensi dan berada di Dusun Nglarang. Teknik samplingnya menggunakan purposive sampling dan sampel kontrolnya sebanyak 31 orang dengan kriteria berusia 4559 tahun, negatif hipertensi dan bertempat tinggal di Dusun Nglarang Desa Triharjo dengan perbandingan 1:1.

Teknik pengambilan data primer dengan melakukan observasi, dokumentasi dan pemeriksaan. Data sekunder diperoleh dari data Dinkes Kabupaten Bantul dan admninitrasi Puskesmas Pandak II. Analisis univariat bertujuan untuk menjelaskan atau mendeskripsikan karakteristik setiap variabel penelitian. Analisis Bivariat yang dilakukan terhadap dua variabel yang diduga berhubungan atau berkorelasi dengan menggunakan uji Chisquare. Penelitian ini telah mendapatkan persetujuan etik dari Komite Etik Penelitian Kesehatan, Sekolah Tinggi Ilmu Kesehatan Surya Global Yogyakarta dengan nomor: 263/KEPK/SG/XI/2019

\section{HASIL}

Berdasarkan hasil penelitian yang dilakukan oleh peneliti dengan membagikan kuesioner kepada 31 responden, diperoleh karakteristik sebagai berikut. 
Tabel 1. Tabel Distribusi Frekuensi Karakteristik Responden di Wilayah Kerja Puskesmas Pandak II Bantul DIY Tahun 2019

\begin{tabular}{|c|c|c|c|c|}
\hline \multirow{3}{*}{ Karakteristik } & \multicolumn{4}{|c|}{ Responden } \\
\hline & \multicolumn{2}{|c|}{ Kasus } & \multicolumn{2}{|c|}{ Kontrol } \\
\hline & Frekuensi & $\begin{array}{c}\text { Persentase } \\
(\%)\end{array}$ & Frekuensi & Persentase $(\%)$ \\
\hline \multicolumn{5}{|l|}{ Jenis Kelamin } \\
\hline Laki-laki & 4 & 12,90 & 4 & 12,90 \\
\hline Perempuan & 27 & 87,09 & 27 & 87,09 \\
\hline \multicolumn{5}{|l|}{ Usia } \\
\hline 45-49 Tahun & 7 & 22,58 & 9 & 29,03 \\
\hline 50-54 Tahun & 7 & 22,58 & 7 & 22,58 \\
\hline 55-59 Tahun & 17 & 54,83 & 15 & 48,38 \\
\hline \multicolumn{5}{|l|}{ Tingkat Pendidikan } \\
\hline Tidak Sekolah & 7 & 22,58 & 1 & 3,22 \\
\hline SD & 17 & 54,84 & 19 & 61,29 \\
\hline SMP & 2 & 6,45 & 3 & 9,68 \\
\hline SMA & 5 & 16,13 & 7 & 22,58 \\
\hline D1-D3 & 0 & 0 & 0 & 0 \\
\hline D4-S1 & 0 & 0 & 1 & 3,22 \\
\hline Pasca Sarjana & 0 & 0 & 0 & 0 \\
\hline \multicolumn{5}{|l|}{ Pekerjaan } \\
\hline PNS & 0 & 0 & 0 & 0 \\
\hline Petani & 9 & 29,03 & 4 & 12,90 \\
\hline Wiraswasta & 6 & 19,35 & 8 & 25,80 \\
\hline Pegawai Swasta & 0 & 0 & 1 & 3,23 \\
\hline Mahasiswa & 0 & 0 & 0 & 0 \\
\hline Ibu Rumah Tangga & 7 & 22,58 & 8 & 25,81 \\
\hline Lain-lain & 9 & 29,03 & 10 & 32,26 \\
\hline \multicolumn{5}{|l|}{ IMT } \\
\hline Kurang BB Tingkat rendah & 2 & 6,45 & 4 & 12,90 \\
\hline Kurang BB Ringan & 2 & 6,45 & 3 & 9,68 \\
\hline Normal & 15 & 48,39 & 16 & 51,61 \\
\hline Kelebihan BB Tingkat Ringan & 6 & 19,35 & 6 & 19,35 \\
\hline Kelebihan BB Tingkat Berat & 6 & 19,35 & 2 & 6,45 \\
\hline
\end{tabular}

Berdasarkan tabel di atas, dapat diketahui bahwa terdapat 62 responden yang terdiri dari 31 kelompok kasus dan 31 kelompok kontrol. Responden dari kelompok kasus besar berjenis kelamin perempuan yaitu 27 responden lansia dengan persentase $87,09 \%$, sedangkan dari kelompok kontrol mayoritas juga berjenis kelamin perempuan sebanyak 27 lansia dengan persentase $87,09 \%$. Untuk umur pada kelompok kasus mayoritas usianya berkisar antara 55-59 tahun dengan persentase $54,83 \%$, untuk kelompok kontrol mayoritas responden berusia
55-59 tahun dengan persentase 48,38\%. Tingkat pendidikan responden pada kelompok kasus mayoritas SD sebesar 54,84\%, sedangkan dikelompok kontrol mayoritas responden juga mempunyai tingkat pendidikan SD sebesar $61,29 \%$. Pekerjaan responden untuk kelompok kasus mayoritas petani sebesar 29,03\% dan untuk kelompok kontrol mayoritas pekerjaan lain-lain dengan persentase sebesar 32,26\%. Untuk IMT mayoritas berat badan normal untuk kelompok kasus sebesar 48,39\% dan kontrol 51,61 . 


\section{Analisis Data Univariat}

Berdasarkan hasil penelitian didapatkan keturunan, obesitas, dan gaya hidup, yang dapat data distribusi responden berdasarkan variabel dilihat pada table 2 .

Tabel 2. Tabel Distribusi Frekuensi di Wilayah Kerja Puskesmas Pandak II Bantul DIY Tahun 2019

\begin{tabular}{|c|c|c|c|c|}
\hline \multirow{3}{*}{ Variabel } & \multicolumn{4}{|c|}{ Responden } \\
\hline & \multicolumn{2}{|c|}{ Kasus } & \multicolumn{2}{|c|}{ Kontrol } \\
\hline & Frekuensi & Persentase (\%) & Frekuensi & Persentase (\%) \\
\hline \multicolumn{5}{|l|}{ Keturunan } \\
\hline Ada Keturunan & 19 & 61,30 & 6 & 19,35 \\
\hline Tidak Ada Keturunan & 12 & 38,70 & 25 & 80,65 \\
\hline \multicolumn{5}{|l|}{ Obesitas } \\
\hline $\begin{array}{l}\text { Kurang } \\
\text { rendah }\end{array}$ & 2 & 6,45 & 4 & 12,90 \\
\hline Kurang BB Ringan & 2 & 6,45 & 3 & 9,67 \\
\hline Normal & 15 & 48,39 & 16 & 51,61 \\
\hline $\begin{array}{l}\text { Kelebihan BB Tingkat } \\
\text { Ringan }\end{array}$ & 6 & 19,35 & 6 & 19,35 \\
\hline $\begin{array}{l}\text { Kelebihan BB Tingkat } \\
\text { Berat }\end{array}$ & 6 & 19,35 & 2 & 6,45 \\
\hline \multicolumn{5}{|l|}{ Gaya Hidup } \\
\hline Baik & 6 & 19,40 & 17 & 54,80 \\
\hline Cukup & 23 & 74,20 & 13 & 41,90 \\
\hline Kurang & 2 & 6,50 & 1 & 3,20 \\
\hline
\end{tabular}

Berdasarkan tabel di atas, pada kelompok kasus sebagian besar memiliki keturunan hipertensi sebanyak 19 responden $(61,30 \%)$ dan tidak ada keturunan sebanyak 12 responden $(38,70 \%)$. Artinya setiap responden yang mengalami hipertensi pasti memiliki keturunan hipertensi dan setiap responden yang tidak mengalami hipertensi pasti tidak meiliki riwayat keturunan hipertensi dari keluarganya. Pada variabel obesitas yang kurang berat badan tingkat rendah sebanyak 2 responden $(6,45 \%)$, memiliki kurang berat badan ringan sebanyak 2 responden $(6,45 \%)$, dan berat badan normal sebanyak 15 responden $(48,38 \%)$, memiliki berat badan tingkat ringan sebanyak 6 responden $(19,35 \%)$, dan memiliki berat badan tingkat berat sebanyak 6 responden $(19,35 \%)$. Untuk variabel gaya hidup diketahui bahwa dari sebanyak 31 responden sebagian besar memiliki gaya hidup cukup sebanyak 23 responden dengan persentase $74,2 \%$, kelompok responden dengan kriteria baik sebanyak 6 responden dengan persentase 19,4\%, dan kelompok responden dengan kriteria kurang sebanyak 2 responden dengan persentase $6,5 \%$.

\section{Analisis data Bivariat}

Berdasarkan tabel 3 tentang hubungan antara status keturunan hipertensi dengan risiko hipertensi dapat diketahui bahwa persentase tertinggi pada kelompok risiko hipertensi adalah responden yang memiliki riwayat keturunan hipertensi yaitu sebesar $61,30 \%$ 
(19 responden), sedangkan pada kelompok tidak hipertensi adalah responden yang tidak memiliki riwayat keturunan hipertensi sebesar 80,65\% (25 responden). Berdasarkan hasil bivariat dapat diketahui bahwa ada hubungan yang signifikan antara riwayat keturunan hipertensi dengan risiko hipertensi pada Lansia di Wilayah Kerja Puskesmas Pandak II Bantul DIY dengan nilai $p$ sebesar 0,02 ( $p$-value $\leq$ $0,05)$.

Tabel 3. Hasil Crosstabs Keturunan Terhadap Risiko

Hipertensi di Wilayah Kerja Puskesmas Pandak II Bantul DIY Tahun 2019

\begin{tabular}{|c|c|c|c|c|c|c|c|}
\hline \multirow{3}{*}{$\begin{array}{c}\text { Faktor } \\
\text { Keturunan }\end{array}$} & \multicolumn{4}{|c|}{ Kejadian Hipertensi } & \multirow[b]{2}{*}{ Total } & \multirow{3}{*}{$\begin{array}{c}\text { OR } \\
(95 \% \\
\text { CI })\end{array}$} & \multirow{3}{*}{$\begin{array}{c}p \\
\text { value }\end{array}$} \\
\hline & \multicolumn{2}{|c|}{ Hipertensi } & \multicolumn{2}{|c|}{$\begin{array}{c}\text { Tidak } \\
\text { Hipertensi }\end{array}$} & & & \\
\hline & $\mathbf{N}$ & $\%$ & $\mathbf{N}$ & $\%$ & $\mathbf{N}$ & & \\
\hline $\begin{array}{l}\text { Tidak Ada } \\
\text { Keturunan }\end{array}$ & 12 & $38,70 \%$ & 25 & $80,65 \%$ & 37 & & \\
\hline $\begin{array}{l}\text { Ada } \\
\text { Keturunan }\end{array}$ & 19 & $61,30 \%$ & 6 & $19,35 \%$ & 25 & 6,597 & 0,002 \\
\hline Jumlah & 31 & $100.0 \%$ & 31 & $100.0 \%$ & 62 & & \\
\hline
\end{tabular}

Berdasarkan tabel 4 tentang hubungan antara tingkat obesitas dengan resiko hipertensi dapat diketahui bahwa persentase tertinggi pada kelompok hipertensi dan kelompok tidak hipertensi adalah pada status IMT yang sama yaitu normal sebesar $48,38 \%$ atau 15 orang (kasus) dan 51, 61\% atau 16 responden (kontrol).

Tabel 4. Hasil Crosstabs Obesitas Terhadap Resiko Hipertensi di Wilayah Kerja Puskesmas Pandak II Bantul DIY Tahun 2019

\begin{tabular}{|c|c|c|c|c|c|c|}
\hline \multirow{3}{*}{$\begin{array}{l}\text { Faktor } \\
\text { Obesitas }\end{array}$} & \multicolumn{4}{|c|}{ Kejadian Hipertensi } & \multirow{3}{*}{ Total } & \multirow{3}{*}{$\begin{array}{c}P \\
\text { value }\end{array}$} \\
\hline & \multicolumn{2}{|c|}{ Hipertensi } & \multicolumn{2}{|c|}{$\begin{array}{c}\text { Tidak } \\
\text { Hipertensi } \\
\end{array}$} & & \\
\hline & $\mathbf{N}$ & $\%$ & $\mathbf{N}$ & $\%$ & & \\
\hline $\begin{array}{l}\text { Kurang } \\
\text { BB } \\
\text { Tingkat } \\
\text { Rendah }\end{array}$ & 2 & $6,45 \%$ & 4 & $12,90 \%$ & 6 & \\
\hline $\begin{array}{l}\text { Kurang } \\
\text { BB } \\
\text { Tingkat } \\
\text { Ringan }\end{array}$ & 2 & $6,45 \%$ & 3 & $9,67 \%$ & 5 & \\
\hline Normal & 15 & $48,38 \%$ & 16 & $51,61 \%$ & 31 & 0,575 \\
\hline $\begin{array}{l}\text { Kelebihan } \\
\text { BB } \\
\text { tingkat } \\
\text { Ringan }\end{array}$ & 6 & $19,35 \%$ & 6 & $19,35 \%$ & 12 & \\
\hline $\begin{array}{l}\text { Kelebihan } \\
\text { BB } \\
\text { Tingkat } \\
\text { Berat }\end{array}$ & 6 & $19,35 \%$ & 2 & $6,45 \%$ & 8 & \\
\hline Total & 31 & $100 . \%$ & 31 & $100 . \%$ & 62 & \\
\hline
\end{tabular}

Hasil analisis bivariat dari variabel obesitas dengan risiko hipertensi (table 4) didapatkan bahwa tidak terdapat hubungan yang signifikan antara status obesitas dengan resiko hipertensi pada lansia di Wilayah Kerja Puskesmas Pandak II Bantul DIY dengan nilai $p=0,575$ ( $p$-value $\geq$ $0,05)$.

Berdasarkan tabel 5 tentang hubungan antara gaya hidup dengan hipertensi pada lansia dapat diketahui bahwa persentase tertinggi pada kelompok hipertensi adalah Lansia yang memiliki status gaya hidup yang cukup yaitu $74,2 \%$ (23 responden) dan pada kelompok tidak hipertensi adalah pada gaya hidup baik sebesar 54,8\% (17 responden). Hasil analisis bivariat didapatkan bahwa terdapat hubungan yang signifikan antara gaya hidup dengan resiko hipertensi pada lansia di Wilayah Kerja Puskesmas Pandak II Bantul DIY dengan nilai $p=0,015$ ( $p$-value $\leq 0,05)$.

Tabel 5. Hasil Crosstabs Gaya Hidup Terhadap Resiko Hipertensi di Wilayah Kerja Puskesmas Pandak II Bantul DIY Tahun 2019

\begin{tabular}{lccccccc}
\hline Variabel & \multicolumn{4}{c}{ Kejadian Hipertensi } & & \multirow{2}{*}{$\begin{array}{c}\text { P } \\
\text { Gaya }\end{array}$} & \multicolumn{2}{c}{ Hipertensi } & \multicolumn{2}{c}{ Normal } & Total & value \\
\cline { 2 - 5 } Hidup & $\mathbf{N}$ & $\%$ & $\mathbf{N}$ & $\%$ & & \\
\hline Kurang & 2 & 6,5 & 1 & 3,2 & 3 & 0,015 \\
Cukup & 23 & 74,2 & 13 & 41,9 & 36 & \\
Baik & 6 & 19,4 & 17 & 54,8 & 23 & \\
Total & 31 & 100 & 31 & 100 & 62 & \\
\hline
\end{tabular}


PEMBAHASAN

Pengaruh Faktor Keturunan Terhadap

Risiko Hipertensi pada Lansia di Wilayah Kerja Puskesmas Pandak II Bantul DIY Tahun 2019.

Berdasarkan hasil analisis uji ChiSquare didapatkan hasil yang signifikan dengan nilai $p(0,002) \leq p \alpha(0,05)$ yang artinya adalah ada hubungan yang signifikan antara faktor keturunan atau riwayat keturunan dengan hipertensi dengan risiko hipertensi pada lansia di Wilayaj Kerja Puskesmas Pandak II Bantul DIY pada tahun 2019.

Peran faktor genetik terhadap timbulnya hipertensi terbukti dengan ditemukannya kejadian bahwa hipertensi lebih banyak pada kembar monozigot (satu sel telur) daripada heterozigot (berbeda sel telur). ${ }^{2}$ Tidak setiap penderita hipertensi di dapat dari garis keturunan, tetapi seseorang memeliki potensi untuk mendapat hipertensi jika orang tuanya adalah penderita hipertensi. Keturunan atau genetik juga merupakan salah satu faktor risiko terjadinya hipertensi yang tidak dapat diubah. ${ }^{3}$ Faktor genetik tidak bisa dikendalikan. Adanya faktor genetik pada keluarga tertentu akan menyebabkan keluarga itu mempunyai risiko menderita hipertensi. ${ }^{4}$

Seperti penelitian terdahulu tentang faktor-faktor yang berpengaruh terhadap kejadian hipertensi pada lansia di wilayah kerja Puskesmas Maiwa Kabupaten Enrekang diperoleh hasil adanya pengaruh antara faktor genetik terhadap hipertensi berdasarkan tabel Chi Kuadrat diperoleh nilai X2 hitung $=41,819$ dan $\mathrm{X} 2 \mathrm{tab}=3,841$ dengan taraf signifikan 5\%. Karena X2 hitung > X2 tabel, ini berarti Ha diterima dan Ho ditolak. ${ }^{5}$

Menurut Suriatun (2018) dengan judul analisis faktor-faktor yang mempengaruhi kejadian hipertensi di Posyandu Lansia Dusun Pundung Ngototirto Gamping Sleman Yogyakarta diperoleh pengaruh yang sangat signifikan dengan menggunakan uji statistik Kendal tau didapatkan $p$-value 0,042 dengan taraf signifikan 5\% maka $p(0,042)<0,05$ yang artinya terdapat pengaruh riwayat keluarga dengan kejaidan hipertensi. ${ }^{6}$

Sejalan dengan penelitian dengan judul faktor-faktor yang berhubungan dengan kejadian hipertensi pada kelompok lanjut usia di Wilayah Kerja UPT Puskesmas Petang I Kabupaten Bandung tahun 2016 di peroleh hasil dengan menggunakan uji chi-Square didapatkan nilai $p=0,019(p<0,05)$ yang artinya terdapat pengaruh riwayat keluarga dengan kejadian hipertensi. ${ }^{7}$

\section{Pengaruh Faktor Obesitas Terhadap Risiko Hipertensi pada Lansia di Wilayah Kerja Puskesmas Pandak II Bantul DIY Tahun 2019.}

Berdasarkan asumsi peneliti bahwa meskipun responden dalam hal ini mayoritas obesitas yang mengalami hipertensi namun sebagian besar berada pada rentang hipertensi ringan dan sedang. Pengujian hasil signifikan hubungan indeks mass tubuh (IMT) dengan kejadian hipertensi menggunakan uji statistik kendall tau didapatkan p-value 0,575 dengan taraf siginifikan 5\% maka $p$-value $(0,0,575) \geq 0,05$ yang artinya tidak ada hubungan indeks massa tubuh (IMT) atau status obesitas Lansia di Wilayah Kerja Puskesmas Pandak II Bantul DIY tahun 2019.

Penelitian ini sejalan dengan penelitian yang dilakukan Arifinn tentang faktor-faktor yang berhubungan dengan kejadian hipertensi pada kelompok lanjut usia di wilayah kerta UPT Puskesmas Petang I Kabupaten Bandung tahun 2016. Berdasarkan penelitian ini didapatkan hasil yaitu dalam analisis bivariat, data status gizi lansia dikategorikan menjadi dua yaitu obesitas dan tidak obesitas. Hasil uji ChiSquare untuk menentukan hubungan antara obesitas dengan kejadian hipertensi. Jumlah lansia yang mengalami hipertensi lebih banyak pada lansia yang tidak obesitas dibandingkan dengan lansia yang mengalami obesitas. Hasil uji statistik menggunakan Chi-Square didapatkan hasil nilai $p=0,271(p>0,05)$ artinya tidak terdapat hubungan yang bermakna antara obesitas dengan kejadian hipertensi. Hasil nilai $\mathrm{RP}=1,179(\mathrm{RP}>1)$, yang artinya obesitas merupakan faktor risiko untuk terjadinya hipertensi. ${ }^{7}$ 
Pengaruh Faktor Gaya Hidup Terhadap Risiko Hipertensi pada Lansia di Wilayah Kerja Puskesmas Pandak II Bantul DIY Tahun 2019.

Hasil uji chi square didapatkan nilai df (person chi square) sebesar 2 dengan taraf signifikasi 0,05 maka nilai $p=0,015$ $\leq$ nilai signifikan $(0,05)$. Berdasarkan hasil tersebut maka Ha diterima, yang artinya bahwa ada pengaruh yang signifikan antara gaya hidup terhadap kejadian hipertensi pada lansia di Wilayah Kerja Puskesmas Pandak II Bantul DIY Tahun 2019.

Penelitian ini sejalan dengan penelitian yang dilakukan oleh Suoth, Meylen dengan judul jurnal hubungan gaya hidup dengan kejadian hipertensi di Puskesmas Kolongan Kecamatan Kalawat Kabupaten Minahasa Utara diperoleh hasil terdapat hubungan gaya hidup mempengaruhi terjadi penyakit hipertensi. Hasil penelitian ini menunjukkan konsumsi makanan didapat nilai signifikan $(p)=0,004$ dengan demikian $\mathrm{Ha}$ diterima dan $\mathrm{Ho}$ ditolak. Aktivitas fisik didapat nilai signifikan $(p)=0,000$ dengan demikian Ho diterima $\mathrm{Ha}$ ditolak. Stres didapat nilai signifikan $(p)=0,002$ dengan demikian $\mathrm{Ha}$ diterima dan Ho ditolak, kesimpulannya gaya hidup sangat mempengaruhi terjadinya penyakit hipertensi. ${ }^{8}$

Sejalan dengan penelitian yang telah dilakukan oleh Taslima dengan judul hubungan riwayat keluarga dan gaya hidup dengan hipertensi pada lansia di Puskesmas Kuta Alam Banda Aceh diperoleh hasil terdapat hubungan antara gaya hidup dengan hipertensi. Hasil penelitian dengan uji chi square didapatkan $p$ value sebesar $0,027 \leq 0,05$ artinya $\mathrm{Ha}$ diterima atau terdapat hubungan yang signifikan antara gaya hidup dengan hipertensi pada lansia di Puskesmas Kuta Alam Banda Aceh Tahun 2016. ${ }^{9}$

\section{KESIMPULAN}

Dari hasil penelitian yang telah dilakukan, terdapat 2 variabel yang berhubungan yaitu keturunan hipertensi dan gaya hidup sedangkan variabel obesitas pada lansia tidak terdapat hubungan dengan risiko hipertensi di wilayah kerja Puskesmas Pandak II Bantul DIY.

\section{DAFTAR PUSTAKA}

1. Lucky A. Hipertensi: The Silent Killer. Jakarta: Yayasan Penerbitan Ikatan Dokter Indonesia; 2010.

2. Zuraidah, Maksuk, Apriliadi N. Analisis Faktor Risiko Penyakit Hipertensi pada Masyarakat di Kecamatan Kemuning Kota Palembang. J Kesehat Poltekkes Palembang [Internet]. 2012;1(10):1708. Available from: poltekespalembang.ac.id

3. Anies. Waspada Ancaman Penyakit Tidak Menular. Jakarta: PT. Elex Media Kompetindo; 2006.

4. Isnan N, Lestari IG. Pengaruh Self Management Terhadap Tekanan Darah Lansia Yang Mengalami Hipertensi. Indones J Heal Sci. 2018;2(1).

5. Yuli HS, Usman, Makhrajani M. Faktor-faktor yang Berhubungan terhadap Kejadian Hipertensi pada Lansia di Wilayah Kerja Puskesmas Maiwa Kabupaten Enrekang. J Ilm Mns dan Kesehat [Internet]. 2019;2(1). Available from: https://jurnal.umpar.ac.id/index.php/ma kes/article/view/125

6. Suriatun, Ruhyana. Analisis Faktor faktor Yang Mempengaruhi Kejadian Hipertensi di Posyandu Lansia Dusun Pundung Nogotirto Gamping Sleman Yogyakarta. Aisyiyah Yogyakarta; 2018.

7. Arifin M, Weta IW, Ratnwati NLK. Faktor-faktor yang Berhubungan dengan Kejadian Hipertensi pada Kelompok Lanjut Usia di Wilayah Kerja UPT Puskesmas Petang I Kabupaten Bandung. J Med Udayana [Internet]. 2016;5(7). Available from: https://ojs.unud.ac.id/index.php/eum/art icle/view/21559

8. Suoth M, Bidjuni H, Malara R. Hubungan Gaya Hidup dengan Kejadian Hipertensi di Puskesmas Kolongan Kecamatan Kalawat Kabupaten Minahasa Utara. J Keperawatan. 2014;2(1).

9. Taslima, Husna A. Hubungan Riwayat Keluarga dan Gaya Hidup Dengan Hipertensi pada Lansia di Puskesmas Kuta Alam Banda Aceh. J Heal Care Technol Med. 2017;3(1). 